This item was submitted to Loughborough's Research Repository by the author.

Items in Figshare are protected by copyright, with all rights reserved, unless otherwise indicated.

\title{
An LED-based photovoltaic measurement system with variable spectrum and flash speed
}

PLEASE CITE THE PUBLISHED VERSION

PUBLISHER

PVSEC / Elsevier

LICENCE

CC BY-NC-ND 4.0

REPOSITORY RECORD

Bliss, Martin, Thomas R. Betts, and Ralph Gottschalg. 2019. "An Led-based Photovoltaic Measurement System with Variable Spectrum and Flash Speed". figshare. https://hdl.handle.net/2134/5075. 
This item was submitted to Loughborough's Institutional Repository (https://dspace.lboro.ac.uk/) by the author and is made available under the following Creative Commons Licence conditions.

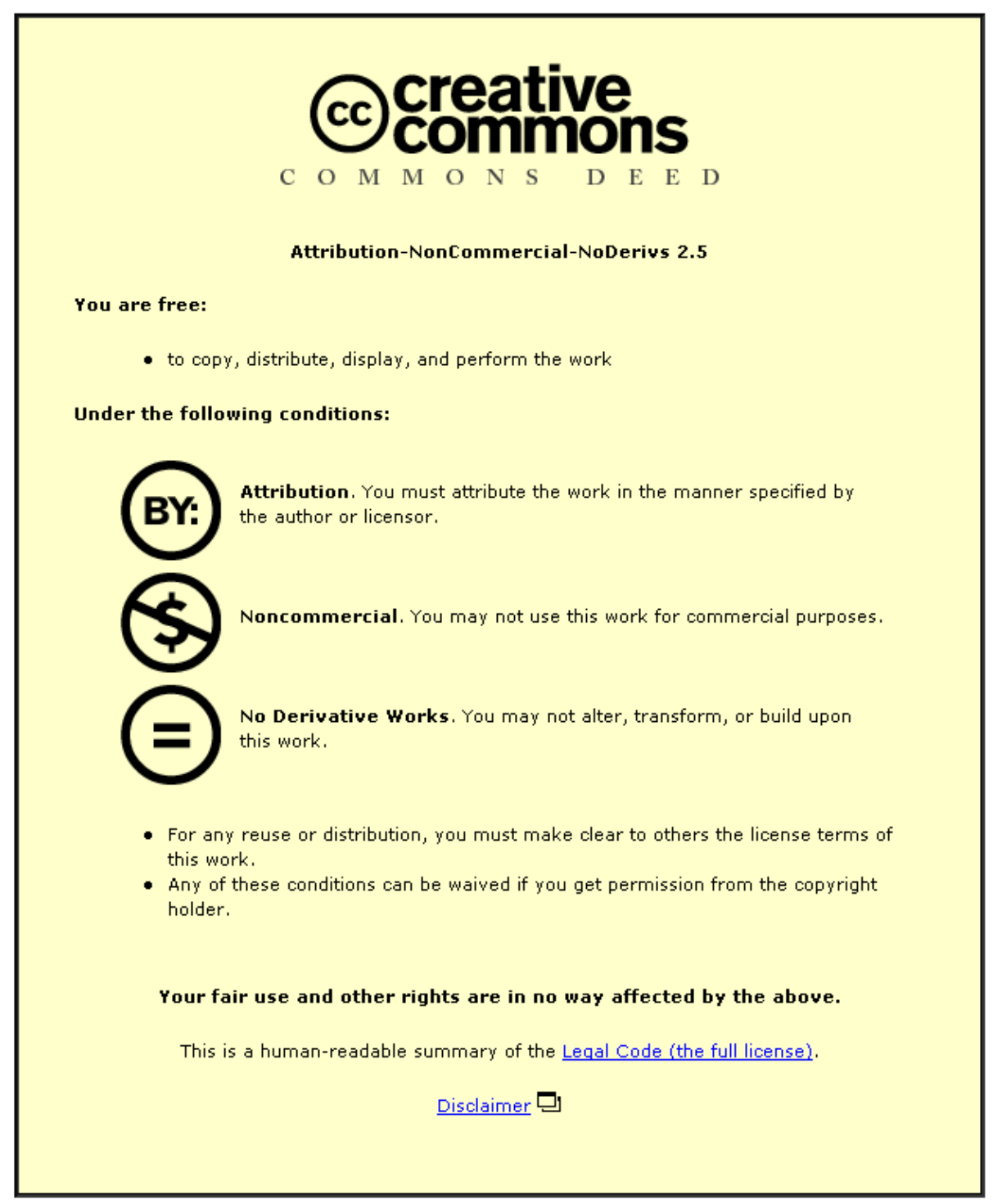

For the full text of this licence, please go to: http://creativecommons.org/licenses/by-nc-nd/2.5/ 


\title{
AN LED-BASED PHOTOVOLTAIC MEASUREMENT SYSTEM WITH VARIABLE SPECTRUM AND FLASH SPEED
}

\author{
M. Bliss*, T.R. Betts, R. Gottschalg \\ Centre for Renewable Energy Systems Technology, Department of Electronic and Electrical Engineering, \\ Loughborough University, Loughborough, Leicestershire, LE11 3TU, United Kingdom \\ Corresponding e-mail: M.Bliss@lboro.ac.uk
}

\begin{abstract}
Outdoor environmental variability leads to the need of artificial illumination systems for PV module characterisation. The two main solar simulator types in use for this purpose, steady state and flash simulators, each have advantages and disadvantages regarding practicality of use and breadth of applicability. To combine the advantages of both types and eliminate the disadvantages, an LED-based solar simulator has been developed, capable of producing light in variable flash speeds and pulse shapes or as a continuous light for long-term measurements. The system features full control of all light sources allowing variable intensity and spectral distribution during measurements.

The paper gives a technical description of the measurement system. The results of the initial qualification tests and initial measurements are included.
\end{abstract}

\section{INTRODUCTION}

Advances in photovoltaic technologies, specifically multijunction devices, have increased the complexity of indoor measurements. Both solar simulator types in use today, steady state and flash, each have advantages and disadvantages. For example, a steady state simulator can deliver highly accurate measurements, but causes thermal instability during the measurements and has high operation and maintenance costs. With a flash simulator the device maintains its temperature and operating costs are lower, but care must be taken to avoid measurement artefacts such as capacitive effects [1], which can distort IV curves and lead to inaccurate power rating. For combining the advantages of both simulator types and to eliminate their disadvantages, an LED-based solar simulator prototype has been developed, producing variable flash shapes in variable speeds as well as providing a continuous light.

To date, with conventional simulators, PV devices are generally measured only at different irradiances and temperatures. However, the spectrum can be dynamically adjusted in the system presented here.

\section{TECHNICAL DESCRIPTION}

The simulator LED array consists of 376 LEDs in 8 different colours, to cover the light spectrum from ultraviolet to red. In this prototype, halogen lights are used to cover the infrared part of the spectrum, albeit developments are ongoing to replace this with LEDs in the final product. The control system allows fully separate control and adjustment of the intensities of all light sources. It is possible to closely match the AM $1.5 \mathrm{G}$ spectrum used in standard test conditions (STC) [2], as well as to simulate the change from blue rich to red rich with increasing airmass, as seen during realistic operation. The control system allows flash frequencies of up to $500 \mathrm{~Hz}$ in all imaginable flash shapes, giving rise to a wide range of scientific applications.

For IV tracing, an analog 4-quadrant high-speed operational amplifier power supply is used. To avoid errors due to changing conditions, IV characteristics and irradiance are measured simultaneously. Measurement and IV tracing speed is adjustable and can be as short as $10 \mu$ s per measurement point.

A PV device temperature control system is also embedded in the simulator, capable of regulating the test device temperature from 5 to $85^{\circ} \mathrm{C}$, albeit the lower temperatures might cause condensation on the device.

The system is controlled by a personal computer with in-house developed LabVIEW software.

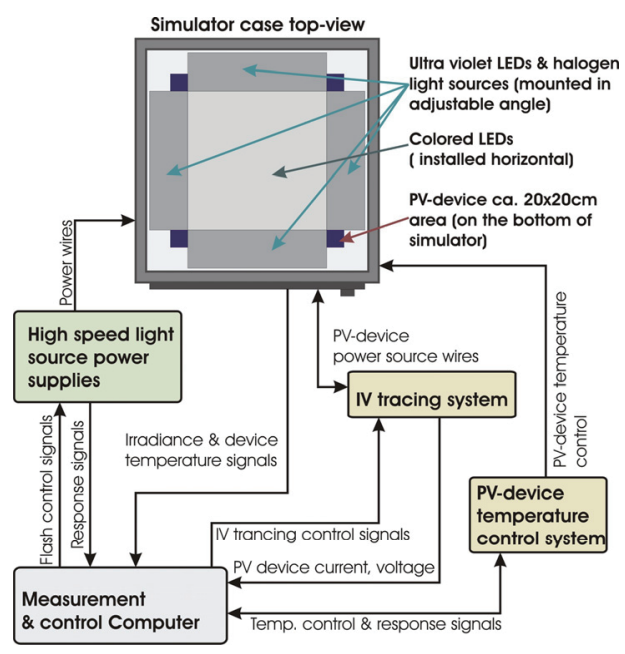

Fig. 1 Schematic overview

\section{QUALIFICATION}

The aim was to investigate the possibility of obtaining a purely LED illuminated system that is 
capable of class A. In the following the prototype is assessed as class B. This allows us to identify methods to optimise the behaviour in the final version.

\subsection{Temporal instability}

The stability of the different light sources has been measured with an K\&Z SPlite centred in the test area.

Due to light source and electronics warm-up times, the stability of the LED and halogen light sources varies in dependence of measurement times between Class $\mathrm{A}$ $(\max \pm 2 \%)$ and Class $C(\max \pm 10 \%)[3]$ (Table I).

Table I. Measured temporal stability at different measurement times and conditions of LEDs, Halogen lights, or all light sources

\begin{tabular}{l|l|r}
\hline $\begin{array}{c}\text { Measurement } \\
\text { condition and setup }\end{array}$ & $\begin{array}{c}\text { Meas. } \\
\text { Time }\end{array}$ & $\begin{array}{c}\text { Temporal } \\
\text { Instability [ } \mathbf{\pm \% ]}\end{array}$ \\
\hline \hline LEDs (250us start-up) & $1 \mathrm{~ms}$ & 0.77 \\
LEDs (250us start-up) & $10 \mathrm{~ms}$ & 1.37 \\
LEDs (250us start-up) & $1000 \mathrm{~ms}$ & 3.76 \\
Halogen (2.5s start-up) & $2.5 \mathrm{~s}$ & 0.44 \\
Halogen (2.5s start-up) & $25 \mathrm{~s}$ & 1.75 \\
All (5s start-up) & $24 \mathrm{~h}$ & 8.35 \\
All (15min warm-up) & $24 \mathrm{~h}$ & 1.32
\end{tabular}

It should be noted, that the given stability is the stability without any feedback, which could be implemented relatively easily. However, depending on the application it is virtually always possible to maintain the two percent required to achieve class A.

\subsection{Spectral output}

As mentioned in the technical description, it is possible to adjust the spectral output of the simulator. Hence the source spectrum (see Fig. 2) has been measured in two configurations: at full intensity of all light sources with no further intensity adjustment and optimized with adjusted intensities for matching the AM1.5G spectrum as closely as possible.

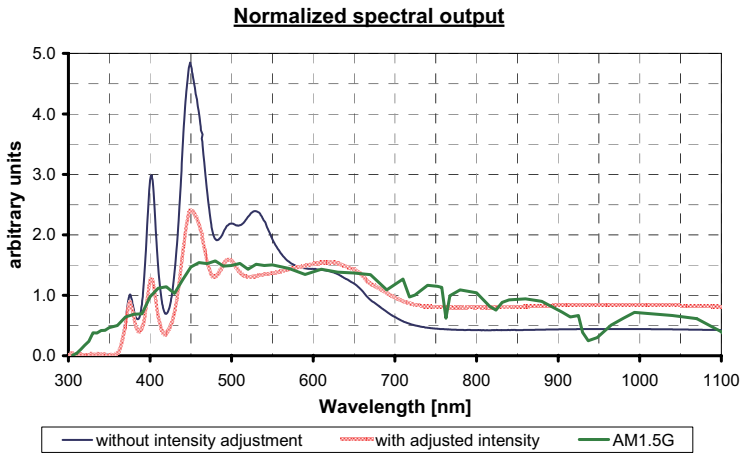

Fig. 2 Simulator light source output spectrum

As shown in Table II, with all light sources at full power, a class $\mathrm{C}$ spectral match was measured. By adjusting the intensity of the different light sources a class B match was achieved [3], which is entirely due to the choice of halogen lights and does not affect the possibility of an LED-only simulator achieving class A.
Table II. Spectral match classification

\begin{tabular}{c|c|c|r|c}
\hline \hline & \multicolumn{2}{|c|}{ Full power } & \multicolumn{2}{c}{ Closest AM1.5 match } \\
$\begin{array}{c}\text { Wavelength } \\
\text { interval [nm] }\end{array}$ & $\begin{array}{c}\text { Relative } \\
\text { Error }\end{array}$ & Class & $\begin{array}{c}\text { Relative } \\
\text { Error }\end{array}$ & Class \\
\hline \hline $400-500$ & 1.85 & $\mathrm{C}$ & 1.01 & $\mathrm{~A}$ \\
$500-600$ & 1.29 & $\mathrm{~B}$ & 0.94 & $\mathrm{~A}$ \\
$600-700$ & 0.84 & $\mathrm{~A}$ & 0.99 & $\mathrm{~A}$ \\
$700-800$ & 0.44 & $\mathrm{C}$ & 0.75 & $\mathrm{~A}$ \\
$800-900$ & 0.48 & $\mathrm{C}$ & 0.89 & $\mathrm{~A}$ \\
$900-1100$ & 0.74 & $\mathrm{~B}$ & 1.40 & $\mathrm{~B}$
\end{tabular}

\subsection{Non-uniformity of irradiance}

A high accuracy thermopile pyranometer was used to measure the light intensity over a $220 \times 220 \mathrm{~mm}$ field in $20 \times 20 \mathrm{~mm}$ resolution.

With the current non-optimised control, class $\mathrm{C}$ is achieved over the test area of $140 \times 140 \mathrm{~mm}$ with nonuniformity of $\pm 8 \%$. The area of $100 \times 100 \mathrm{~mm}$ we achieve a Class B with $\pm 4 \%$ [3]. Further homogeneity measurements of each individual LED colour and the halogen lights have shown that the intensity pattern changes, which means that the spectral output is also changing over the illuminated area. However, due to the control system of the simulator it is possible to set the intensity of each light source separately. At this time, work continues to calculate the calibration factors to optimise the homogeneity over the illuminated area.

\section{CONCLUSIONS}

Qualification of the LED-based simulator prototype shows that achieving the required intensities and qualities of a class AAA solar simulator is not trivial. The shortcomings of the prototype will be adjusted for in the final unit. Furthermore, some LEDs just being released will make the overall energy spectral match even better. The LED based simulator will, however, open many possibilities for the analysis of PV devices.

\section{ACKNOWLEDGEMENTS}

The design and construction of the system is financially supported by EPSRC (EP/D078431/1).

\section{REFERENCES}

[1] C. Monokroussos, et al, "The effects of solar cell capacitance on calibration accuracy when using a flash simulator," Conference Record of the 2006 IEEE 4th World Conference on Photovoltaic Energy Conversion (IEEE Cat. no. 06CH37747), pp. ROM, 2006.

[2] "IEC 60904-3: Measurement Principles for Terrestrial PV Solar Devices with Reference Spectral Irradiance Data," 1989.

[3] "IEC 60904-9: Photovoltaic devices - Part 9: Solar simulator performance requirements," 1995. 